\title{
Eco-friendly Preparation of Epoxy-Rich Graphene Oxide for Wound
}

\section{Healing}

Ying Zheng ${ }^{\mathrm{a} 1}$, Siqiao Li ${ }^{\mathrm{b} 1}$, Daobin Han ${ }^{\mathrm{a} 1}$, Liangsheng Konga ${ }^{\mathrm{a}}$, Jianmin Wanga ${ }^{\mathrm{a}}$, Min Zhao ${ }^{\mathrm{a}}$, Wei Cheng ${ }^{\mathrm{c}}$, Huangxian Jue ${ }^{\mathrm{e}}$ Zhongzhu Yang ${ }^{\mathrm{d}}$, Shijia Dinga ${ }^{\mathrm{a}}$

${ }^{a}$ Key Laboratory of Clinical Laboratory Diagnostics (Ministry of Education), College of Laboratory Medicine, Chongqing Medical University, Chongqing 400016, China ${ }^{b}$ Department of Forensic Medicine, Faculty of Basic Medical Sciences, Chongqing Medical University, Chongqing 400016, China

${ }^{c}$ The Center for Clinical Molecular Medical detection, The First Affiliated Hospital of Chongqing Medical University, Chongqing 400016, China

${ }^{d}$ College of Medical Technology, Chengdu University of Traditional Chinese Medicine, Chengdu 611137, China

eState Key Laboratory of Analytical Chemistry for Life Science, School of Chemistry and Chemical Engineering, Nanjing University, Nanjing 210023, China

*Corresponding author: Tel: +86-23-68485688, Fax: +86-23-68485786.

E-mail address: zzyang@cdutcm.edu.cn (Z.Z. Yang) and dingshijia@163.com (S.J. Ding)

${ }^{1}$ These authors contributed equally to this work. 


\section{Supporting Information}

Table S1. Comparison of antibacterial action between the erGO and other reported nanosized

metals.

\begin{tabular}{|c|c|c|c|c|}
\hline Type of nanomaterials/ & Microorganisms & MIC & MBC & Ref. \\
\hline \multicolumn{5}{|l|}{ combination } \\
\hline $\mathrm{Ag}$ nanoparticles with allicin & S. aureus & $400 \mu \mathrm{g} \mathrm{mL}^{-1}$ & $1.1 \mathrm{ppm}$ & {$[51]$} \\
\hline $\mathrm{MoO}_{3}$ nanoparticles & S. aureus, Enterococci & $700-800 \mu \mathrm{g} \mathrm{mL}^{-1}$ & Not mentioned & {$[52]$} \\
\hline $\mathrm{MgO}$ nanoparticles & E. coli, K. pneumonia, S. aureus & $125-500 \mu \mathrm{g} \mathrm{mL}^{-1}$ & $240 \mu \mathrm{g} \mathrm{mL}^{-1}$ & [53] \\
\hline $\mathrm{ZnO}$ nanoparticles with antibiotics & Enterococci & $2.5 \times 10^{-3} \mathrm{M}$ & $5 \times 10^{-3} \mathrm{M}$ & [54] \\
\hline Ce-doped $\mathrm{TiO}_{2}$ nanoparticles & E. coli & $200 \mu \mathrm{g} \mathrm{mL}^{-1}$ & $>1000 \mu \mathrm{g} \mathrm{mL}^{-1}$ & [55] \\
\hline erGO & E. coli, S. aureus, MRSA, S.pn & $<100 \mu \mathrm{g} \mathrm{mL}^{-1}$ & $160-320 \mu \mathrm{g} \mathrm{mL}^{-1}$ & This work \\
\hline
\end{tabular}

(1) $2 \mathrm{KMnO}_{4}+\mathrm{H}_{2} \mathrm{SO}_{4}=\mathrm{Mn}_{2} \mathrm{O}_{7}+\mathrm{K}_{2} \mathrm{SO}_{4}+\mathrm{H}_{2} \mathrm{O}$ (2:1)

(2) $2 \mathrm{KMnO}_{4}+2 \mathrm{H}_{2} \mathrm{SO}_{4}=\mathrm{MnO}_{3}{ }^{+}+\mathrm{HSO}_{4}{ }^{-}+\mathrm{HMnO}_{4}+\mathrm{K}_{2} \mathrm{SO}_{4}+\mathrm{H}_{2} \mathrm{O}(1: 1)$

(3) $\mathrm{KMnO}_{4}+3 \mathrm{H}_{2} \mathrm{SO}_{4}=\mathrm{K}^{+}+\mathrm{MnO}_{3}{ }^{+}+3 \mathrm{HSO}_{4}{ }^{-}+\mathrm{H}_{3} \mathrm{O}^{+}$(1:3)

Figure S1. The equations of the formation of 2D planar $\mathrm{MnO}_{3}{ }^{+}$. 
A

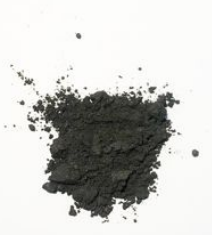

B

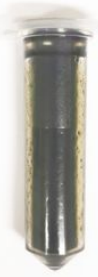

C

Figure S2. (A) Graphite powder. (B) Graphite with the intercalation of $\mathrm{MnO}_{3}{ }^{+}$. (C) erGO nanofilm.
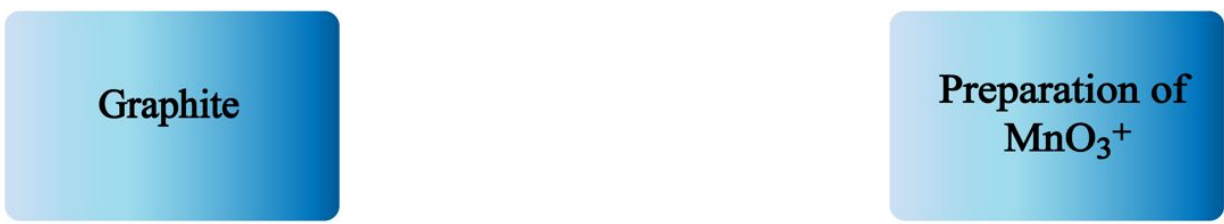

$\mathrm{KMnO}_{4}+3 \mathrm{H}_{2} \mathrm{SO}_{4}=\mathrm{K}^{+}+\mathrm{MnO}_{3}{ }^{+}+3 \mathrm{HSO}_{4}^{-}+\mathrm{H}_{3} \mathrm{O}^{+}(1: 3)$

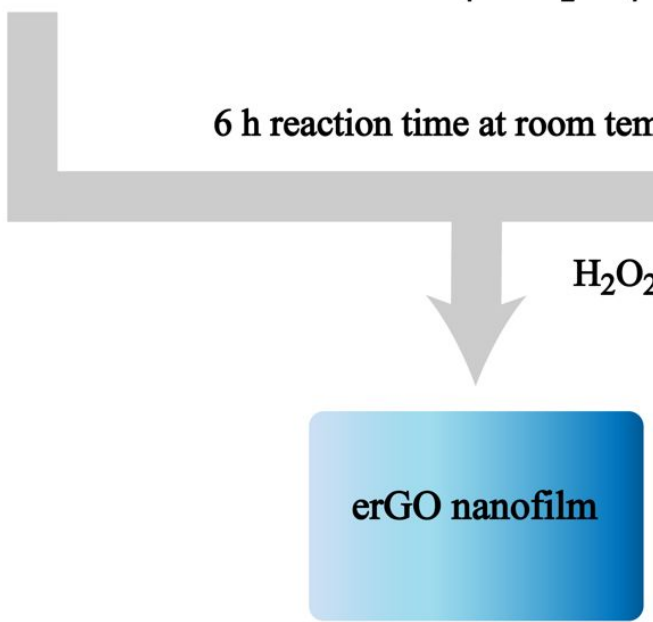

Figure S3. erGO nanofilm synthesis conditions and reagent quantities. 


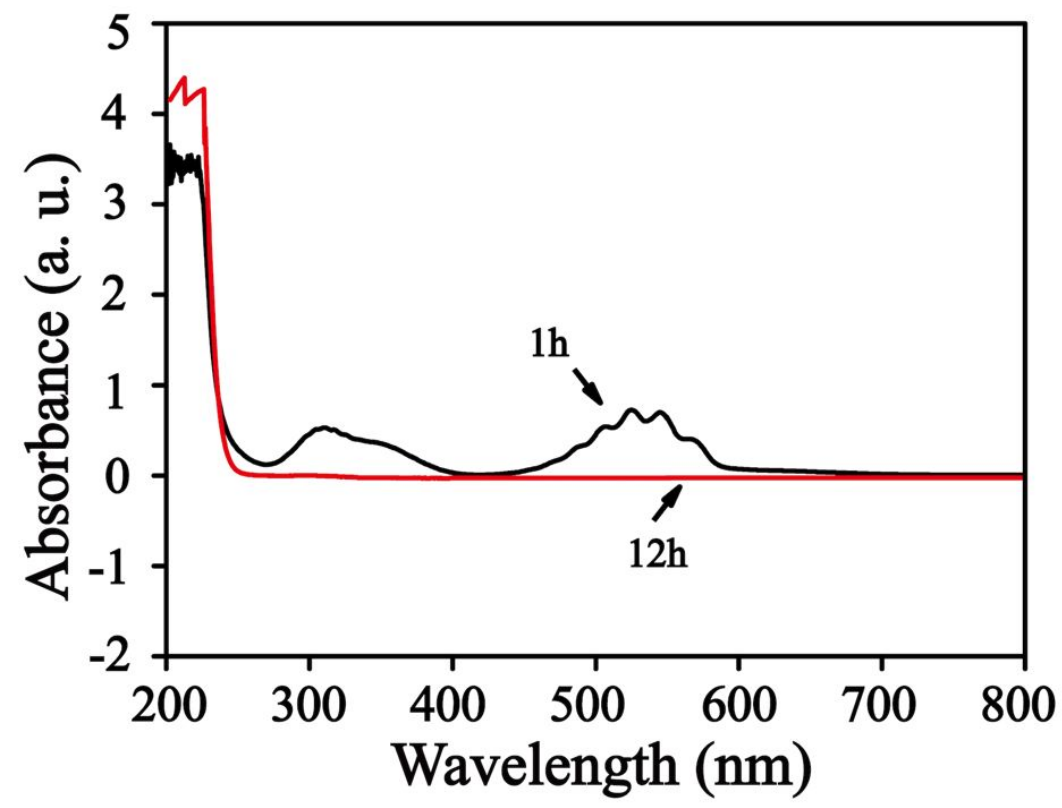

Figure S4. The UV absorption spectrum of $\mathrm{KMnO}_{4}$ : the $-\mathrm{MnO}_{4}$ was embedded in the graphene after $12 \mathrm{~h}$.

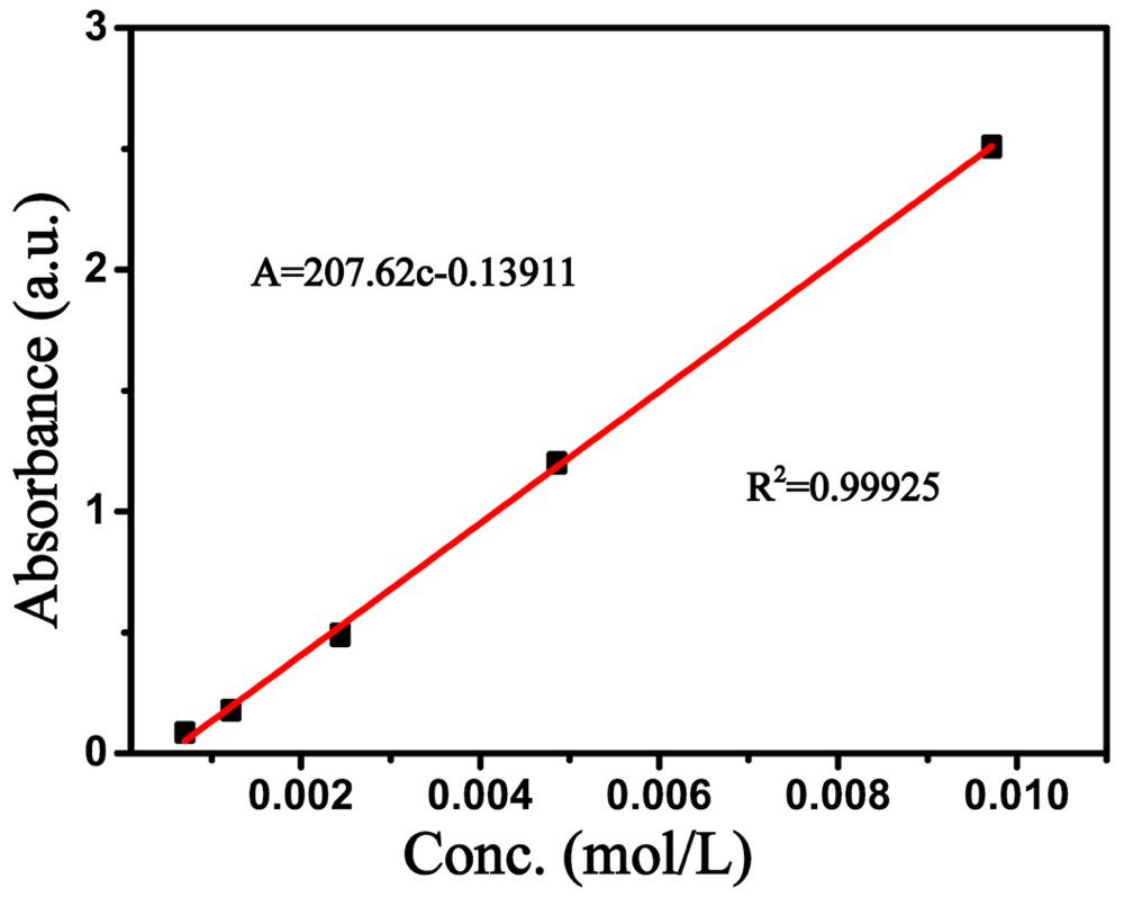

Figure S5. The standard curve of $\mathrm{MnO}_{3}{ }^{+}$. After mixing $\mathrm{KMnO}_{4}$ and $\mathrm{H}_{2} \mathrm{SO}_{4}$, the $\mathrm{MnO}_{3}{ }^{+}$was detected by the UV-visible spectrophotometer at $480 \mathrm{~nm}$. 


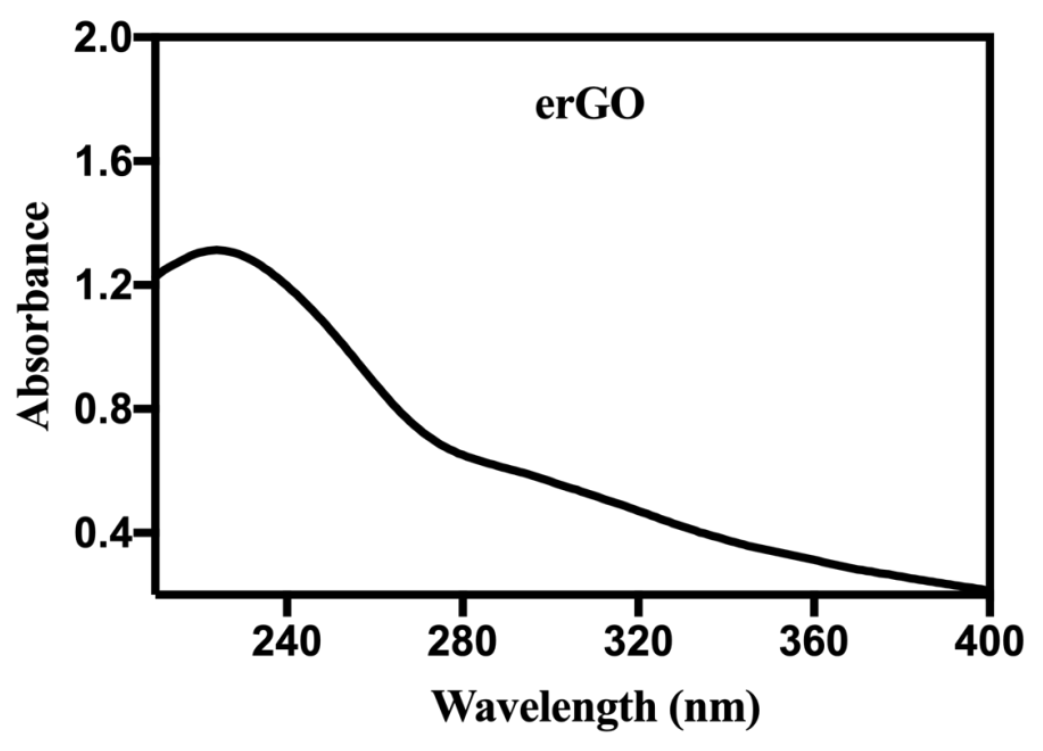

Figure S6. The UV absorption spectrum of erGO nanofilm.

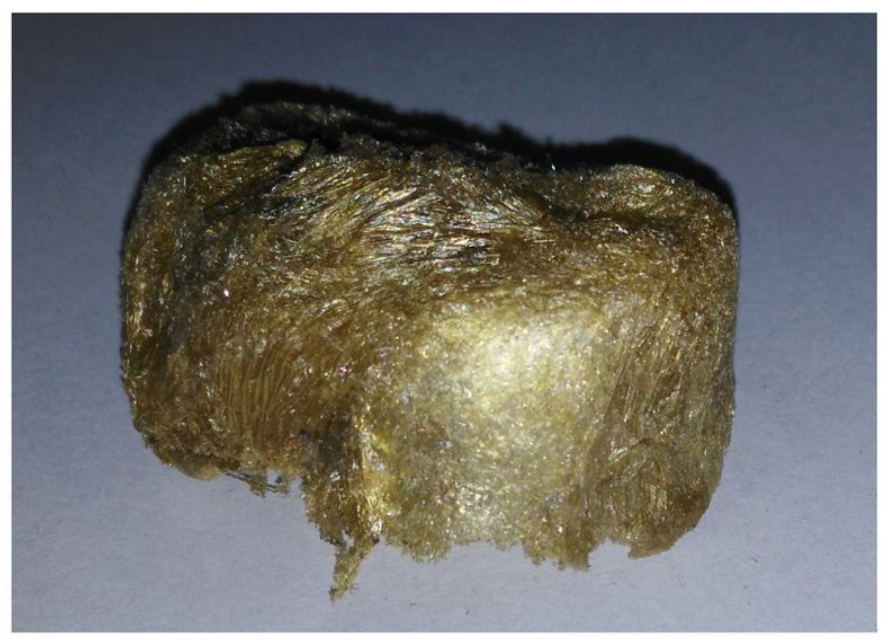

Figure S7. The vacuum freeze-drying of erGO nanofilm. 

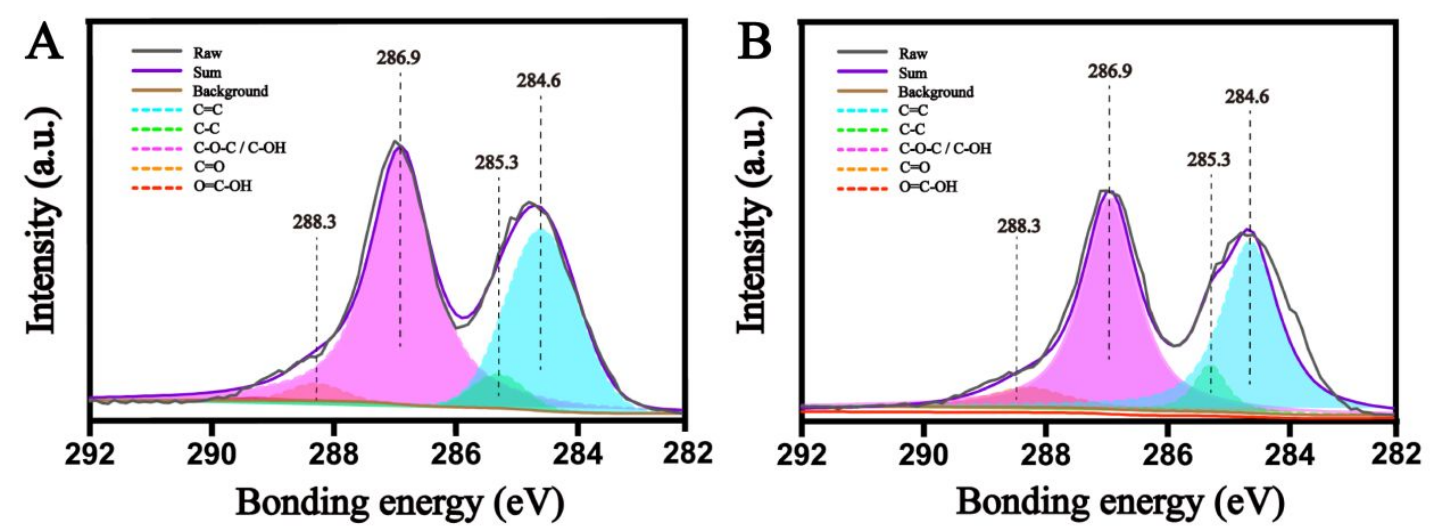

Figure S8. (A) The XPS spectrum of the control groups A (GO-1). (B) The XPS spectrum of the control groups B (GO-2).
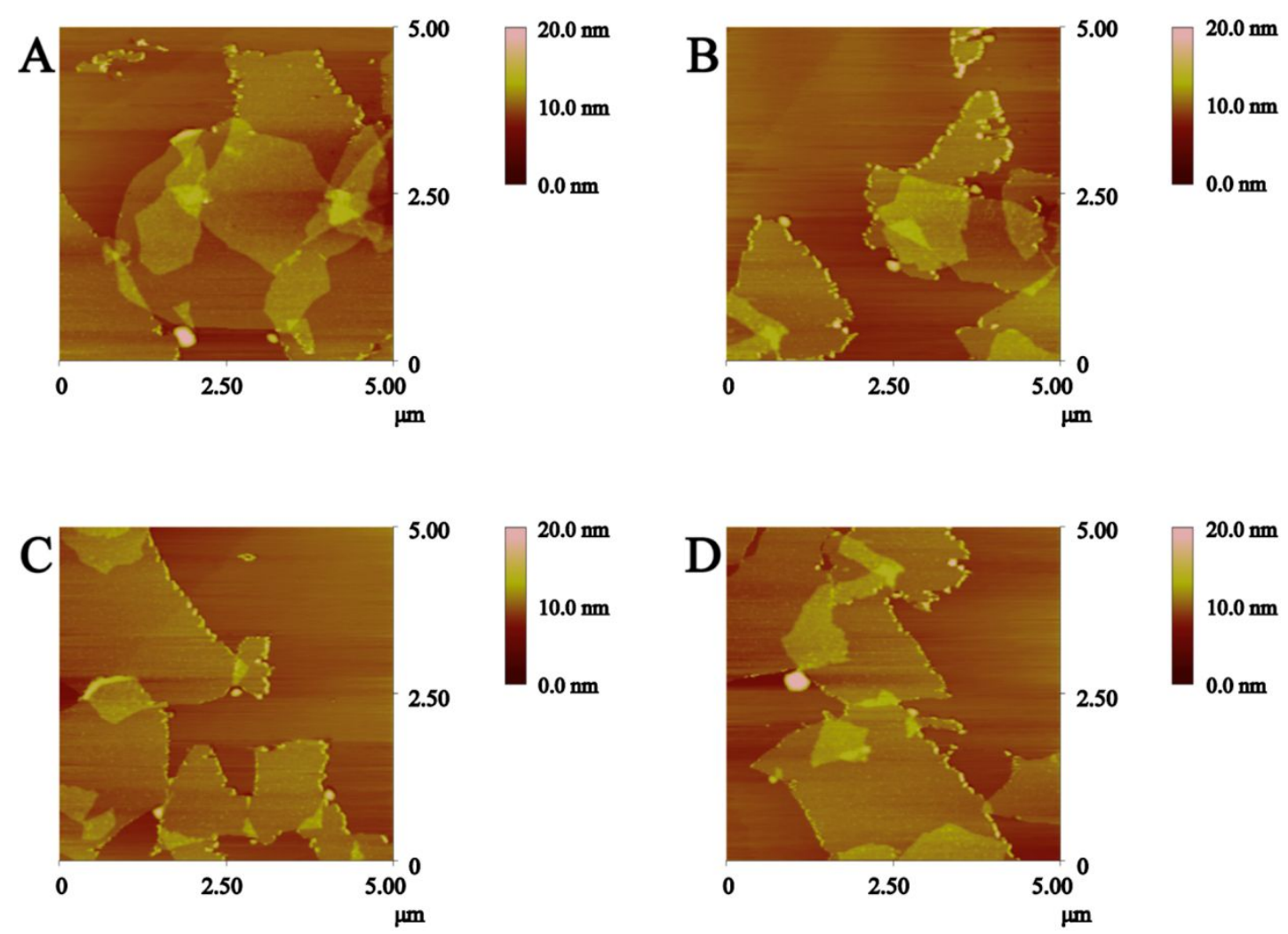

Figure S9. AFM images of erGO nanofilm with $1.131 \mathrm{~nm}$ lamella consisting of the superposition of 2-3 layers. 

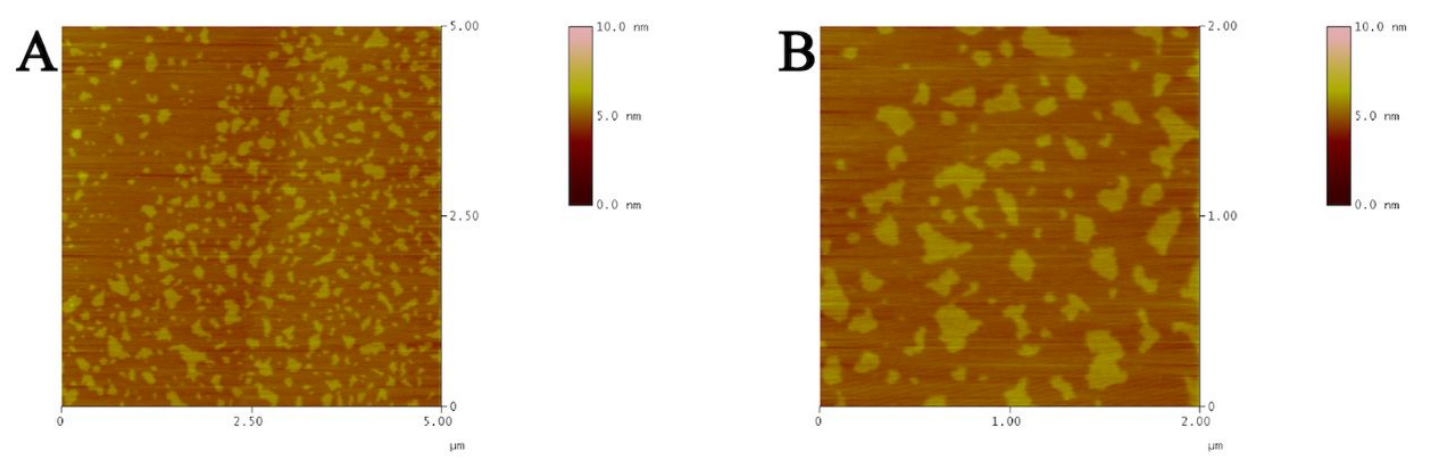

Figure S10. (A) AFM images of the control groups A (GO-1). (B) AFM images of the control groups $\mathrm{B}(\mathrm{GO}-2)$.
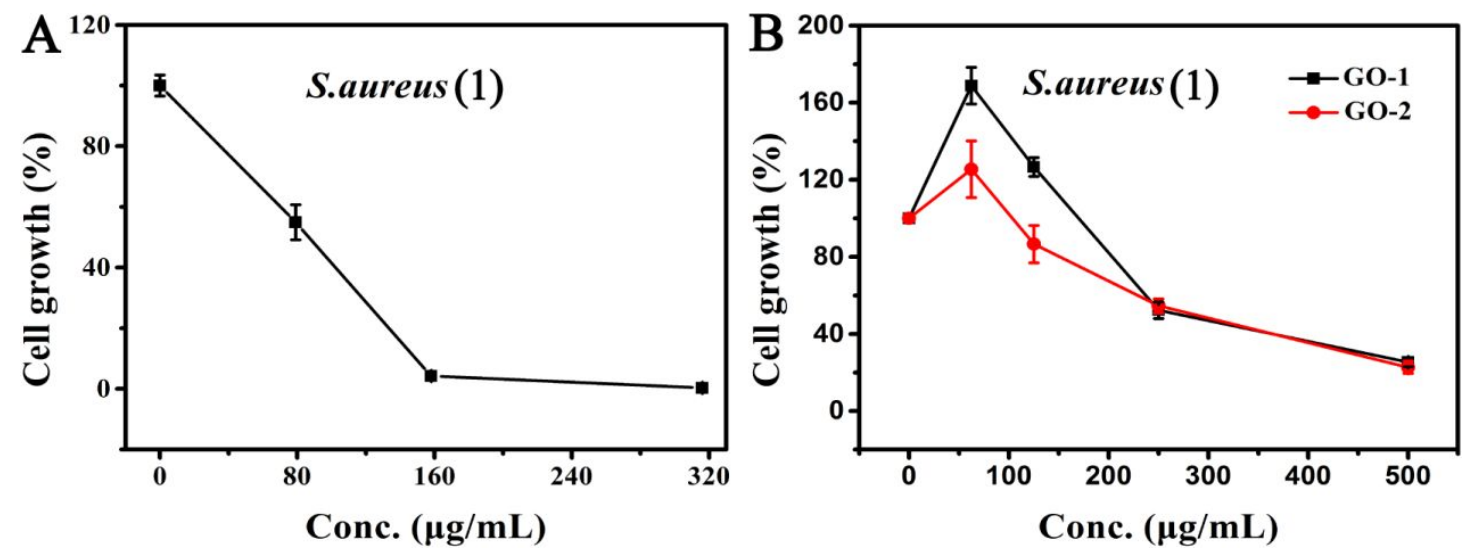

Figure S11. (A) Bacterial killing effects of erGO nanofilm in S. aureus (1). (B) Bacterial killing of erGO nanofilm control groups in S. aureus (1).
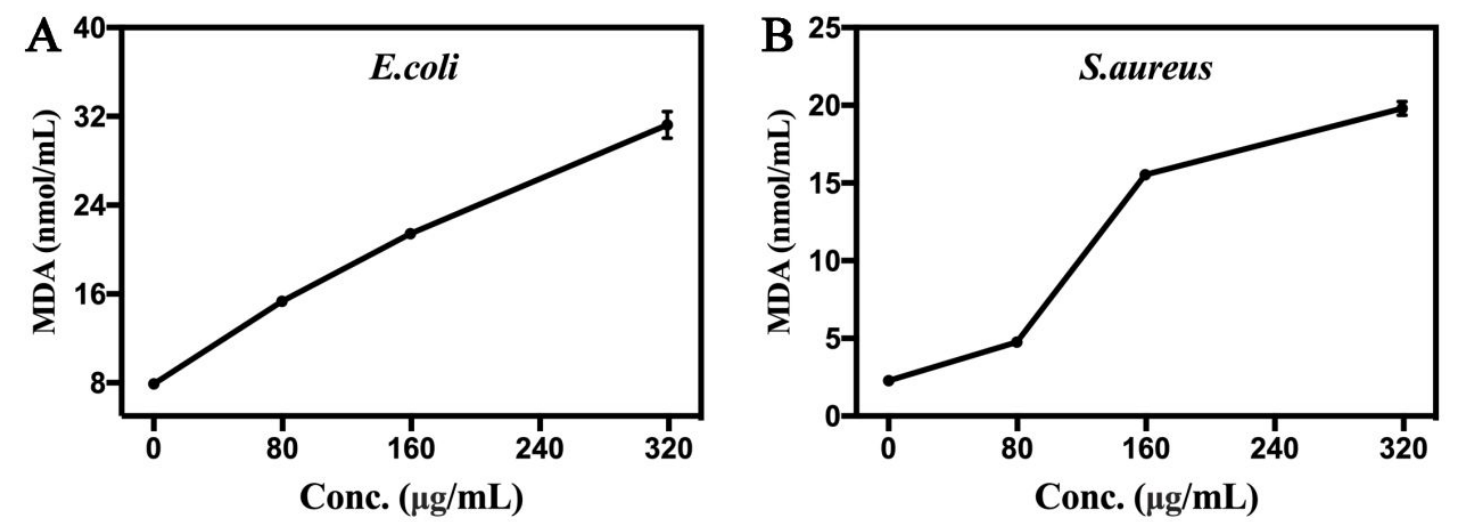

Figure S12. (A) Detection of lipid peroxidation of E. coli (A) and S. aureus (B) after incubating with erGO nanofilm. 

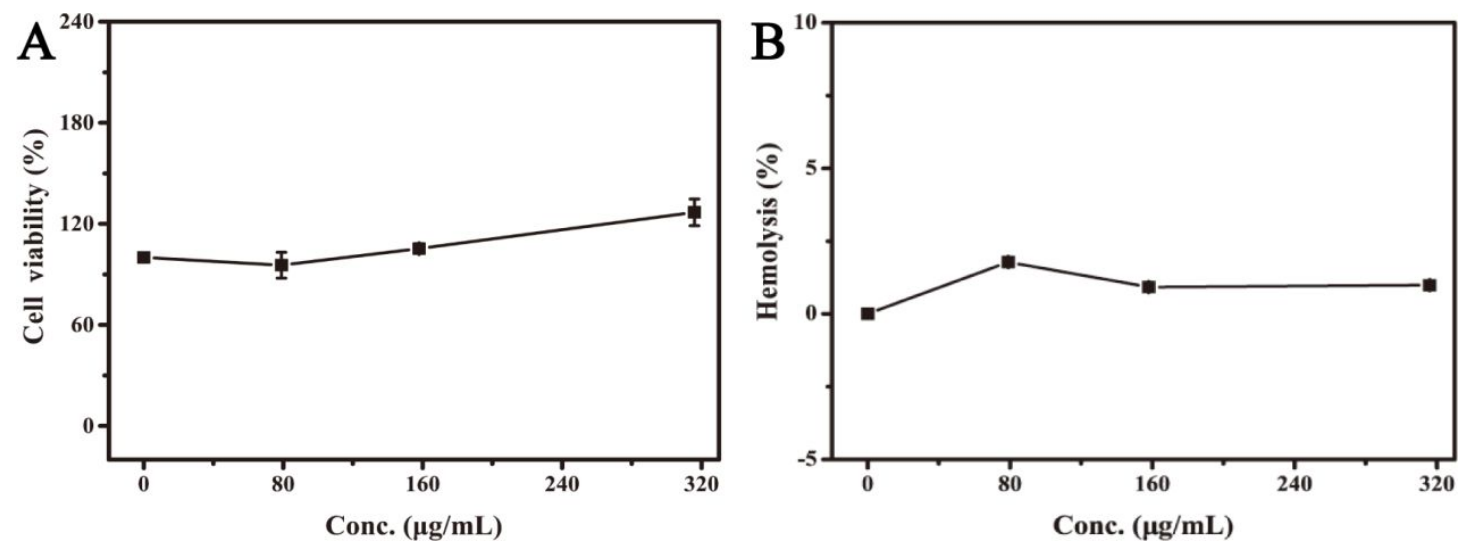

Figure S13. Excellent biocompatibility of the synthetic erGO nanofilm. (A) Cell viability of erGO nanofilm after $24 \mathrm{~h}$ of incubation with the human epithelial cells (B) Hemolysis effect of erGO nanofilm after incubation with red blood cells for $1 \mathrm{~h}$.

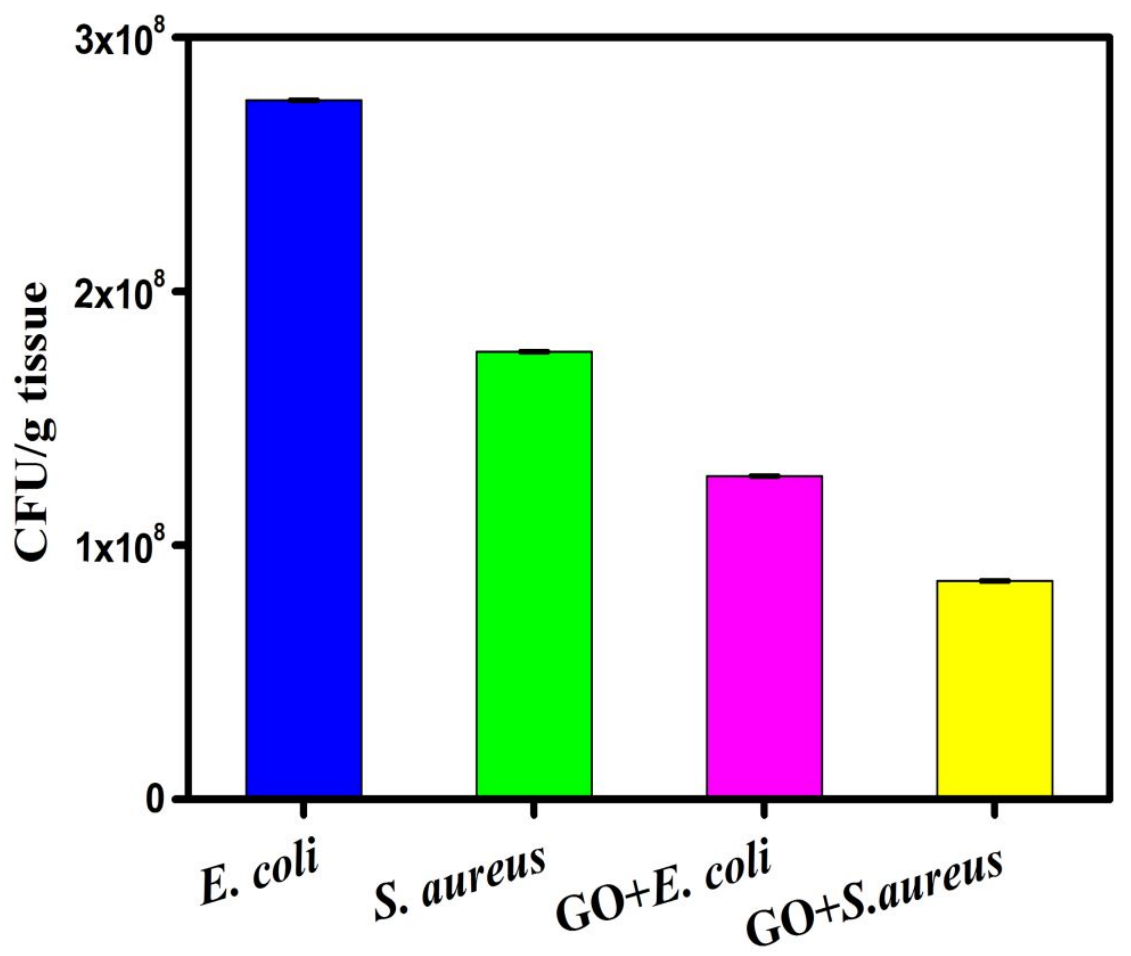

Figure S14. Bacterial counts of E. coli and $S$. aureus after 10-day incubation with the erGO nanofilm and an equal amount of aseptic saline water. 